\title{
Amyloid- $\beta$ precursor protein promotes cell proliferation and motility of advanced breast cancer
}

Seunghwan Lim ${ }^{1 *}$, Byoung Kwon Yoo ${ }^{4}$, Hae-Suk Kim ${ }^{1}$, Hannah L Gilmore ${ }^{2}$, Yonghun Lee ${ }^{3}$, Hyun-pil Lee ${ }^{2}$, Seong-Jin Kim ${ }^{5}$ John Letterio ${ }^{1,6}$ and Hyoung-gon Lee ${ }^{2^{*}}$

\begin{abstract}
Background: Amyloid- $\beta$ precursor protein (APP) is a highly conserved single transmembrane protein that has been linked to Alzheimer disease. Recently, the increased expression of APP in multiple types of cancers has been reported where it has significant correlation with the cancer cell proliferation. However, the function of APP in the pathogenesis of breast cancer has not previously been determined. In this study, we studied the pathological role of APP in breast cancer and revealed its potential mechanism.

Methods: The expression level of APP in multiple breast cancer cell lines was measured by Western blot analysis and the breast cancer tissue microarray was utilized to analyze the expression pattern of APP in human patient specimens. To interrogate the functional role of APP in cell growth and apoptosis, the effect of APP knockdown in MDA-MB-231 cells were analyzed. Specifically, multiple signal transduction pathways and functional alterations linked to cell survival and motility were examined in in vivo animal model as well as in vitro cell culture with the manipulation of APP expression.

Results: We found that the expression of APP is increased in mouse and human breast cancer cell lines, especially in the cell line possessing higher metastatic potential. Moreover, the analysis of human breast cancer tissues revealed a significant correlation between the level of APP and tumor development. Knockdown of APP (APP-kd) in breast cancer cells caused the retardation of cell growth in vitro and in vivo, with both the induction of p2 $7^{\mathrm{kip} 1}$ and caspase-3-mediated apoptosis. APP-kd cells also had higher sensitivity to treatment of chemotherapeutic agents, TRAIL and 5-FU. Such anti-tumorigenic effects shown in the APP-kd cells partially came from reduced pro-survival AKT activation in response to IGF-1, leading to activation of key signaling regulators for cell growth, survival, and pro-apoptotic events such as GSK3- $\beta$ and FOXO1. Notably, knock-down of APP in metastatic breast cancer cells limited cell migration and invasion ability upon stimulation of IGF-1.
\end{abstract}

Conclusion: The present data strongly suggest that the increase of APP expression is causally linked to tumorigenicity as well as invasion of aggressive breast cancer and, therefore, the targeting of APP may be an effective therapy for breast cancer.

Keywords: AKT, Amyloid- $\beta$ precursor protein, Apoptosis, Breast cancer, Invasion, p27 ${ }^{\text {kip1 }}$

\footnotetext{
* Correspondence: sx1269@case.edu; hyoung-gon.lee@case.edu

'Department of Pediatrics, Case Comprehensive Cancer Center, Case Western

Reserve University School of Medicine, 2103 Cornell Road, Cleveland, $\mathrm{OH}$

44106, USA

2Department Pathology, Case Western Reserve University School of Medicine,

2103 Cornell Road, Cleveland, OH 44106, USA

Full list of author information is available at the end of the article
}

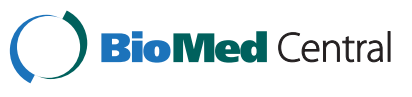

(c) 2014 Lim et al.; licensee BioMed Central Ltd. This is an Open Access article distributed under the terms of the Creative Commons Attribution License (http://creativecommons.org/licenses/by/4.0), which permits unrestricted use, distribution, and reproduction in any medium, provided the original work is properly credited. The Creative Commons Public Domain Dedication waiver (http://creativecommons.org/publicdomain/zero/1.0/) applies to the data made available in this article, unless otherwise stated. 


\section{Background}

Amyloid- $\beta$ precursor protein (APP) is a highly conserved single transmembrane protein with a receptor-like structure and has been linked with Alzheimer disease [1,2] while its normal physiological function is unclear. Several APP isoforms derived from alternative splicing processes have been reported and diverse products including soluble APP (sAPP) or abnormal amyloid- $\beta$ peptide through $\alpha-, \beta$-, or $\gamma$-secretase-mediated cleavage(s) are post-translationally generated [3,4]. APP is ubiquitously expressed in a broad spectrum of cell types including non-neuronal cells, while the nature of APP has been mainly studied in neuronal cells due to its pathological significance in Alzheimer disease. Several pathophysiological functions of APP have been proposed such as its potential role in cell growth and cell adherence [5-7]. It has been demonstrated that APP is engaged in neuronal growth cone adhesion and plays a role as an independently operating cell adhesion molecule for binding to extracellular matrices such as laminin [6]. Specifically, it has been reported that APP is linked to proliferation of thyroid epithelial cells and epidermal basal cell proliferation [8-11] and, interestingly, the increased expression of APP in several types of cancers including pancreatic, lung, colon and breast cancer has been reported [10-15]. These studies suggested that APP has growthpromoting effect as an autocrine growth factor while the underlying mechanism in the regulation of cellular signaling and gene expression has not been fully explored. The potential role of APP in cancer cell motility is also supported by studies which show APP plays a role in migration of neuronal precursor cells and neurite outgrowth [16,17].

In this study, we explored the pathological role of APP in malignancy of breast cancer and its potential molecular mechanism related with cell proliferation and metastasis. Breast cancer is the most common cancer diagnosed among women worldwide [18] and metastatic breast cancer is significantly correlated with poor prognosis and a main cause of death while the underlying molecular pathogenic mechanism still remains to be delineated. We found that the expression level of APP is mechanistically linked with tumorigenicity and malignancy of breast cancer. APP knockdown (APP-kd) in breast cancer cells reduced cell growth via $\mathrm{p} 27^{\mathrm{kip} 1}$ induction, promoting apoptosis, increasing sensitivity to therapeutic treatments, and delayed cell migration and invasion ability upon stimulation. These results suggest that targeting APP may effectively suppress the growth and invasion of malignant breast cancer cells.

\section{Methods}

\section{Cell culture and reagents}

MDA-MB-231 cells were grown in DMEM, and 67NR, 4T07, and 4T1 breast cancer cell lines were grown in
RPMI supplemented with $10 \%$ (vol/vol) FBS, penicillin (100 units/ml), and streptomycin $(100 \mu \mathrm{g} / \mathrm{ml}$; Invitrogen, Rockville, MD). The four human breast cancer cell lines MCF10A1 (M-I), MCF10AT1k.cl2 (M-II), MCF10CA1h (M-III), and MCF10CA1a.cl1 (M-IV) were obtained from Dr. Anita Roberts (NCI/NIH, Bethesda, MD). M-I, M-II, M-III, and M-IV cells were grown in DMEM/F12 (Invitrogen, Carlsbad, CA) containing 5\% horse serum (Invitrogen) at $37^{\circ} \mathrm{C}$ with $5 \% \mathrm{CO}_{2}$. M-I and M-II cells were supplemented additionally with $10 \mu \mathrm{g} / \mathrm{ml}$ insulin (Sigma, St. Louis, MO), $20 \mathrm{ng} / \mathrm{ml}$ epidermal growth factor (Sigma), 0.5 $\mu \mathrm{g} / \mathrm{ml}$ hydrocortisone (Sigma), and $100 \mathrm{ng} / \mathrm{ml}$ cholera toxin (Sigma). Antibodies specific for APP (22C11) were purchased from EMD Millipore; APP (4G8) from Covance. Specific antibodies for p27(C-19) and p21 (F-5) were from Santacruz and anti- $\beta$-actin (AC-15) was from Sigma. Antibodies purchased from Cell Signaling were AKT (\#9772), pAKT Thr308 (\#4056), pAKT Ser473 (\#9271), pFOXO1 Thr24 (\#9464), pGSK3 Ser9 (\#9336), pp65 Ser536 (\#3033), pERK1/2 (\#9101), $\beta$-Catenin (\#9562), PARP (\#9542), and cleaved Caspase-3 (\#9661). Anti-survivin antibody (AB8228) was purchased from Abcam. The antiCD44 antibody (\#15675-1-AP) was from Proteintech group and anti-GSK3b (KAP-ST002E) antibody was from Stressgen.

\section{Knockdown of human APP using lentiviral infection system}

Knockdown of human endogenous APP gene expression was carried out using the lentivirus shRNA expression system and experimental method as previously described [19]. The target sequence of human APP (shAPP-5: 5'CCCTGTTCATTGTAAGCACTT, shAPP-7: 5'-GCAG ACACAGACTATGCAGAT) or control luciferase was used. In order to produce viral particles, the shRNA constructs and virus packaging plasmids were transfected into fresh $293 \mathrm{~T}$ cells and then harvested the viral supernatant and filtered through $0.45 \mu \mathrm{m}$ syringe filter prior to infection. Target cells were infected with virus by spinning at $2000 \mathrm{rpm}$ for $30 \mathrm{~min}$. Semi-quantitative RT-PCR and immunoblotting were carried out to measure knock-down efficiency.

\section{Western blotting and RT-PCR}

The cells were harvested and lysed in RIPA buffer. Equal amounts of protein were loaded and separated in SDSPAGE gel and then transferred to PVDF membrane. The blot was incubated in blocking solution (5\% milk/TBST) and then incubated with primary antibody followed by incubation with secondary HRP conjugated antibody for 1 or 2 hours. The blot was washed 3 times for 5 minutes with TBST between the incubations. Eventually, the change of target protein expression was detected by conducting reaction with Chemiluminescent Substrate (Thermo Scientific), 
exposing, and developing the film. RT-PCR for measuring the level of APP mRNA expression was performed with the primers specific to human APP [20].

\section{Detection of apoptotic cell population}

MDA-MB-231 cells $\left(5 \times 10^{4}\right)$ freshly infected with shLuc, shAPP-5, or shAPP-7 lentiviral particles were immediately seeded in 6-well plates. In order to detect early apoptotic events, we employed Annexin V staining method (eBioscience) which can detect phosphatidylserine on the outer plasma membrane upon initiation of apoptosis. Cell viability staining was carried out using propidium iodide (PI) to identify early-stage apoptotic cells. The FACS analysis was immediately followed after staining the cells.

\section{Cell growth assay}

The control and APP-kd of MDA-MB-231cells $\left(2 \times 10^{3}\right)$ were seeded in 6-well plate in triplicate and maintained in normal growth medium. The sub-confluently growing cells were counted using coulter counter (Beckman) at day 2 and 4 .

\section{Wound-healing assay and cell invasion assay}

To compare the cell motility, the MDA-MB-231 control (shluc) or APP knockdown (shAPP-7) MDA-MB-231 cells were examined in wound healing assay. The confluently grown cells were wounded with $200 \mu \mathrm{l}$ tips and followed by either no treatment or treated with IGF-1 $(25 \mathrm{ng} / \mathrm{ml}$ ) for 18 hours in $0.1 \%$ serum containing medium. Subsequently, cells were fixed with $2 \%$ paraformaldehyde and then stained with rapid 3 step staining set (Richard-Allen Scientific) for clear visualization of migrated cells. The initial wounded edges were marked with dotted lines. Representative results from at least three independent experiments are shown. Cell invasion assays were performed by seeding cells in Boyden chamber (BD Bioscience) coated with matrigel in serum-free medium with or without IGF-1 $(50 \mathrm{ng} / \mathrm{ml})$ in the bottom of each wells for 18 hours. The migrated cells were visualized by staining and photographing under the microscope.

\section{Xenograft mouse model}

The breast cancer cells were seeded freshly prior to injection. The control and shAPP MDA-MB-231 $\left(1 \times 10^{6}\right)$ cells were prepared in the solution (1:1) of PBS and growth factor-reduced matrigel and followed by injection into athymic nude mice subcutaneously. Primary tumor outgrowth was monitored every 4 days by taking measurements of the tumor length $(L)$ and width $(W)$. Tumor volume was calculated as $\pi L W^{2} / 6$ [21]. The mice were maintained up to 6 weeks and sacrificed for tumor excision. The tumor growth was compared to the counterpart and imaged. All animal housing and procedures were performed in compliance with guidelines established by the Institutional Animal Care and Use Committee at Case Western Reserve University.

\section{Immunohistochemistry}

The breast cancer tissue array was purchased from US Biomax (Cat\# BRC961). For immunohistochemistry for the APP detection, the tissue microarrays were hydrated through two changes of xylene and descending ethanol solutions for $10 \mathrm{~min}$ each, followed by a $30 \mathrm{~min}$ submersion in $3 \% \mathrm{H}_{2} \mathrm{O}_{2}$ and finally Tris-buffered saline (TBS). The slides were incubated in $10 \%$ normal goat serum (NGS) in TBS for 30 min and the primary antibody was applied overnight. A monoclonal antibody specific to APP, 22C11 (recognizing the N-terminal domain of full length amyloid- $\beta$ precursor protein; EMD Millipore, 1:250), was applied to the microarrays and then the peroxidase-anti-peroxidase technique was employed and developed with 3'-3'-diaminobenzidine (Dako).

\section{Statistical analysis}

Data are presented as means \pm standard deviation. Differences between the experimental groups were compared with Student's paired two tailed t-test. A p-value less than 0.05 was considered statistically significant.

\section{Results}

\section{The level of APP expression is linked to malignancy of} breast cancer cells

In order to investigate the correlation between APP expression and malignancy of breast cancer, the expression level of APP was examined in a series of human and mouse breast cancers with increasing malignancy. The four human breast cancer cell lines MCF10A1 (M-I), MCF10AT1k.cl2 (M-II), MCF10CA1h (M-III), and MCF10CA1a.cl1 (M-IV) were used in which M-I cells are spontaneously immortalized from normal breast epithelial cells whereas M-II, MIII, and M-IV cells are derived from M-I cells transformed with Ha-Ras oncogene [22,23]. M-III cells are a welldifferentiated tumor derived from M-II xenografts while M-IV cells are a poorly differentiated metastatic tumor derived from xenografts of M-II cells. In our analysis, the total APP expression of both mature (upper band) and immature (lower band) forms was significantly elevated approximately 2 to 7-fold in MCF10A (M-II, -III, and -IV) cells compared to M-I cells (Figure 1A). This positive correlation between APP expression and malignancy was further confirmed in mouse breast cancer cells; 67NR, 4T07, and 4T1 cells which are derived from the same primary tumor [24]. 67NR cells, which can form primary tumors without metastatic ability, showed negligible APP expression whereas highly tumorigenic 4T07 and metastatic 4T1 cells express APP up to 8-fold (Figure 1B). These results suggest that APP is functionally linked to the aggressiveness in breast 


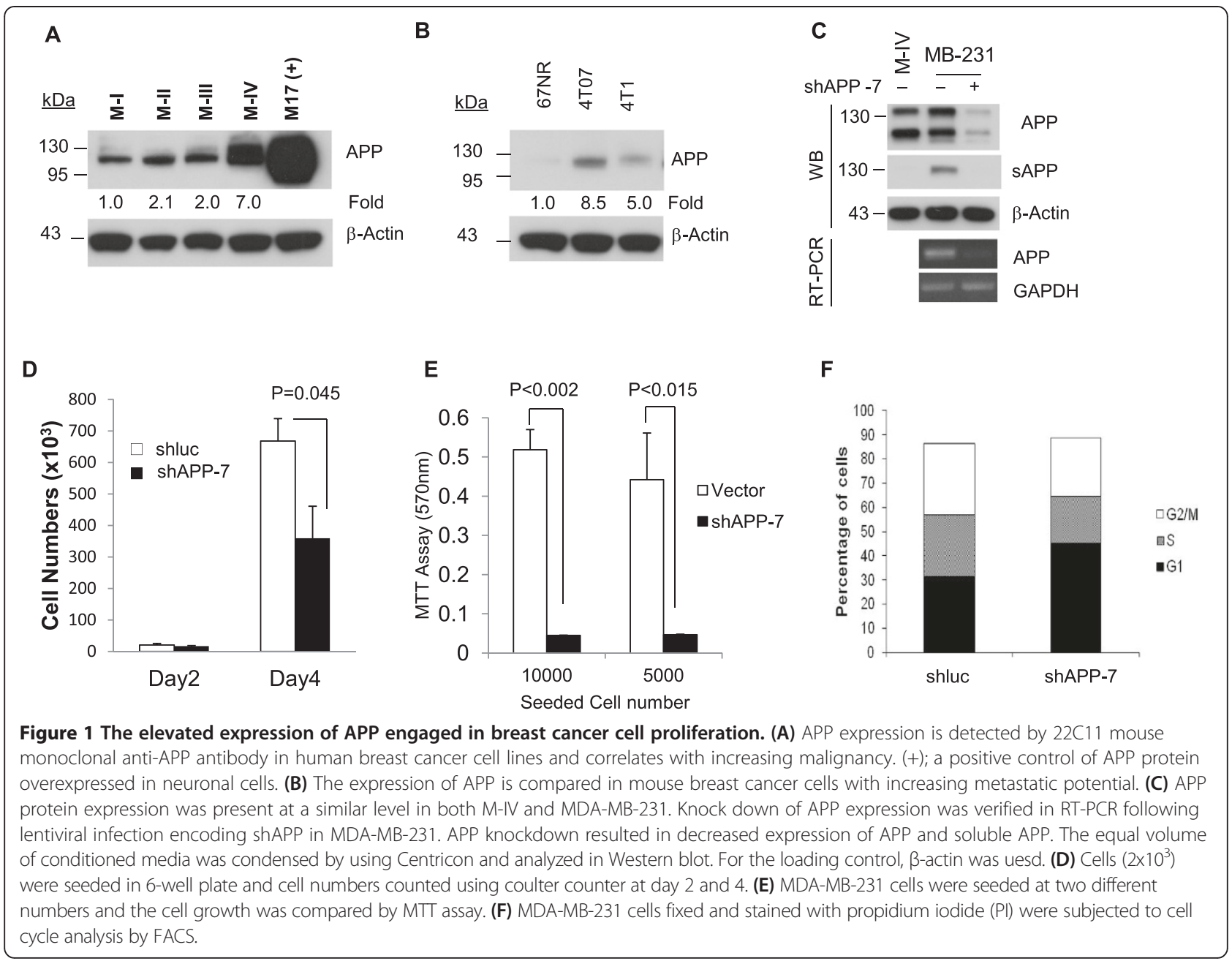

tumor cells and contribute to maintaining their malignancy such as tumorigenic and metastatic ability.

\section{Reduction of the expression of APP prevents cell growth in MDA-MB-231 cells}

We investigated the pathophysiological function of APP by knocking it down using the shRNA targeting APP in MDA-MB-231 malignant human breast cancer cells (Figure 1A). Both mRNA and protein expression of APP were markedly reduced in APP-kd cells compared to control cells (Figure 1C). APP protein expression of MDA-MB231 was comparable to that of M-IV cells while MDAMB-231, but not M-IV cells, showed fair amount of soluble APP secretion that is known to enhance cell growth and survival $[25,26]$. Next, we examined cell proliferation in normal growth medium with $10 \%$ FBS in the control (shluc) and APP-kd (shAPP) cells. Consistent with our hypothesis, reduction of APP expression significantly affected cell proliferation and viability (Figure 1D,E). To confirm the effect of APP on cell growth further, we performed FACS analysis to determine cell cycle phase.
The cell cycle analysis showed that APP-kd cells were arrested largely in G1 phase (45.2\%) compared to control (31.4\%), but low percentage of APP-kd cells (19.4\%) was in $\mathrm{S}$ phase as compared to that of control cells (25.5\%) (Figure 1F). Retarded cell growth and G1 arrest of APP-kd cells suggest that APP is likely engaged in expression of cell cycle inhibitors working on G1 phase such as p2 $7^{\text {kip1 }}$ and $\mathrm{p} 21^{\mathrm{cip} 1}[27,28]$.

APP enhances cell proliferation via regulation of p2 $7^{\text {kip } 1}$

To address whether APP regulates G1 phase cell cycle inhibitors, the control and APP-kd cells grown in normal growth medium were examined to compare $\mathrm{p} 27^{\mathrm{kip} 1}$ and/ or $\mathrm{p} 21^{\text {cip } 1}$ expression of APP-kd cells to control. In our analysis, the level of $\mathrm{p} 27^{\mathrm{kip} 1}$ was dramatically induced in APP-kd cells compared to control (Figure 2A and 2B). However, p $21^{\text {cip } 1}$ expression was unchanged or slightly affected by APP knockdown in multiple cell lines (M-I, M-IV and MDA-MB-231) (Figure 2B and 2C) suggesting that APP regulates cell cycle by modulating p27 $27^{\text {kip } 1}$ specifically. 
It has been established that $\mathrm{p} 27^{\mathrm{kip} 1}$ has dual function as either a tumor suppressor or promoter because nuclear p2 ${ }^{\text {Kip } 1}$ works as an anti-proliferative protein, while cytoplasmic p $27^{\mathrm{kip} 1}$ promotes cytoskeleton remodeling that is important for tumor cell motility and dissemination. In particular, subcellular location of $\mathrm{p} 27^{\mathrm{Kip} 1}$ is significantly correlated with survival of breast cancer patients $[29,30]$. In order to verify functional competency of $\mathrm{p} 27^{\mathrm{kip} 1}$ as a cell cycle inhibitor, we analyzed cellular localization of p2 $7^{\text {kip1 }}$ with immunocytochemistry. A substantial amount of p27 $7^{\mathrm{kip} 1}$ is still located in nuclear compartment of APP$\mathrm{kd}$ cells even after one hour in serum-containing medium (Figure 2D). Conversely, in control cells, p2 $7^{\text {kip } 1}$ located in nuclei required much longer exposure time to be displayed owing to the substantial decrease of total protein with $10 \%$ serum stimulation, and potentially the redistribution of p $27^{\text {kip } 1}$ to cytoplasmic compartment. These results indicate that serum-sensitive signaling pathways regulating $\mathrm{p} 27^{\mathrm{kip} 1}$ expression and cytoplasmic translocation were skewed by
APP knockdown. These data also suggest that APP plays a crucial role for cell proliferation of malignant breast cancers by modulating the expression of cyclin-dependent kinase inhibitor, $\mathrm{p} 27^{\mathrm{kip} 1}$.

\section{APP modulates breast cancer cell survival}

The reduction of breast tumor growth may result not only from blocking cell cycle progression but also the induction of programmed cell death. Thus, we examined if knockdown of APP expression induces cell death in MCF10A and MDA-MB-231 cell lines. Knocking down of APP in M-II cells significantly induced apoptotic markers such as cleavage product of PARP and cleaved caspase- 3 in contrast to the normal immortalized M-I cells which did not sensitively induce such apoptotic markers. Moreover, M-III and M-IV showed such apoptotic markers to a much greater extent (Figure 3A), suggesting that the cell survival of advanced breast cancer cells is more dependent on APP expression than non-

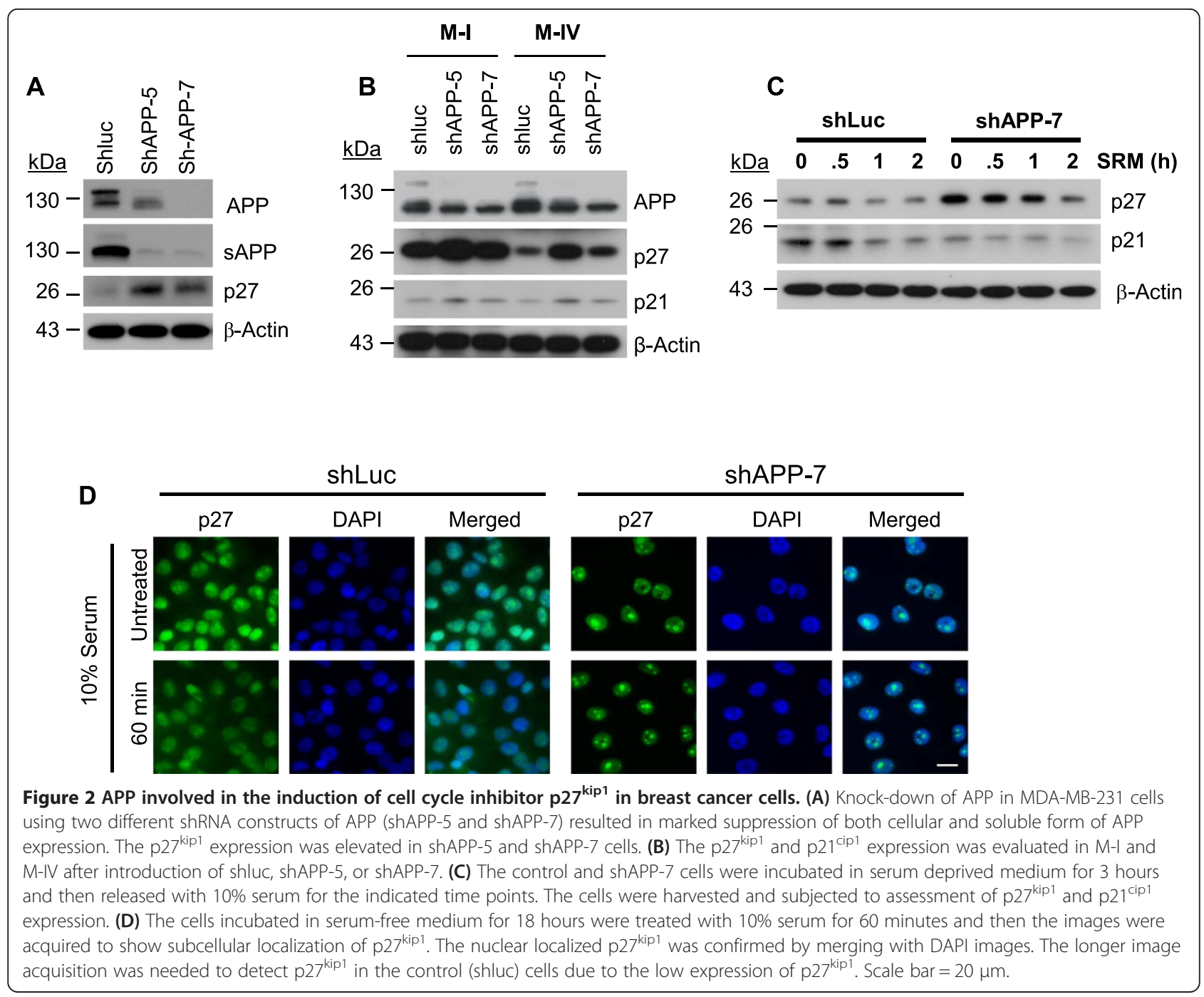


malignant breast epithelial cells (M-I). Next, we assessed the induction of apoptotic markers in MDA-MB-231 and the sensitivity to therapeutic agents such as recombinant tumor necrosis factor (TNF)-related apoptosis-inducing ligand (TRAIL), or 5-Fluorouracil (5-FU). TRAIL has been tested as a potential therapeutic agent for various types of cancer in clinical trials [31], and 5-FU is a conventional chemotherapeutic agent that is commonly used for cancer therapy [32]. The cleaved capase-3 and PARP were augmented in MDA-MB-231 APP-kd cells (shAPP-5 or shAPP-7) (Figure 3B) which were consistent with the results from $\mathrm{M}$-III and M-IV cells (Figure 3A). The induction of apoptosis by knockdown of APP was also confirmed by FACS analysis with staining for Annexin V and propidium iodide (PI). The apoptotic cell populations with Annexin V-high and PI-low were obviously increased in APP-kd cells showing about 25-fold (shAPP-5) and 14fold (shAPP-7) induction as compared to control
(Figure 3C and 3D). These results clearly indicate that APP expression on breast cancer cells is closely interelated with cell survival.

\section{APP affects cell growth in 3D culture and in xenografted mouse model}

In order to solidify the finding of APP functions on cell growth, we employed three-dimensional (3D) cultures of breast cancer cells in reconstituted basement membrane (Matrigel, BD Bioscience). It is widely recognized that the 3D cultures offer many microenvironmental cues which reconstitute in vivo tumor cell behavior [33,34]. The APP-kd MDA-MB-231 cells and its counterpart were cultured in 3D Matrigel up to 7 days. The control MDA-MB-231 cells showed higher tumor growth than APP-kd cells. Interestingly, control MDA-MB-231 cells showed stellate 3D phenotype whereas APP-kd cells displayed more round forms (Figure $4 \mathrm{~A}$ and $4 \mathrm{~B}$ ). Since the

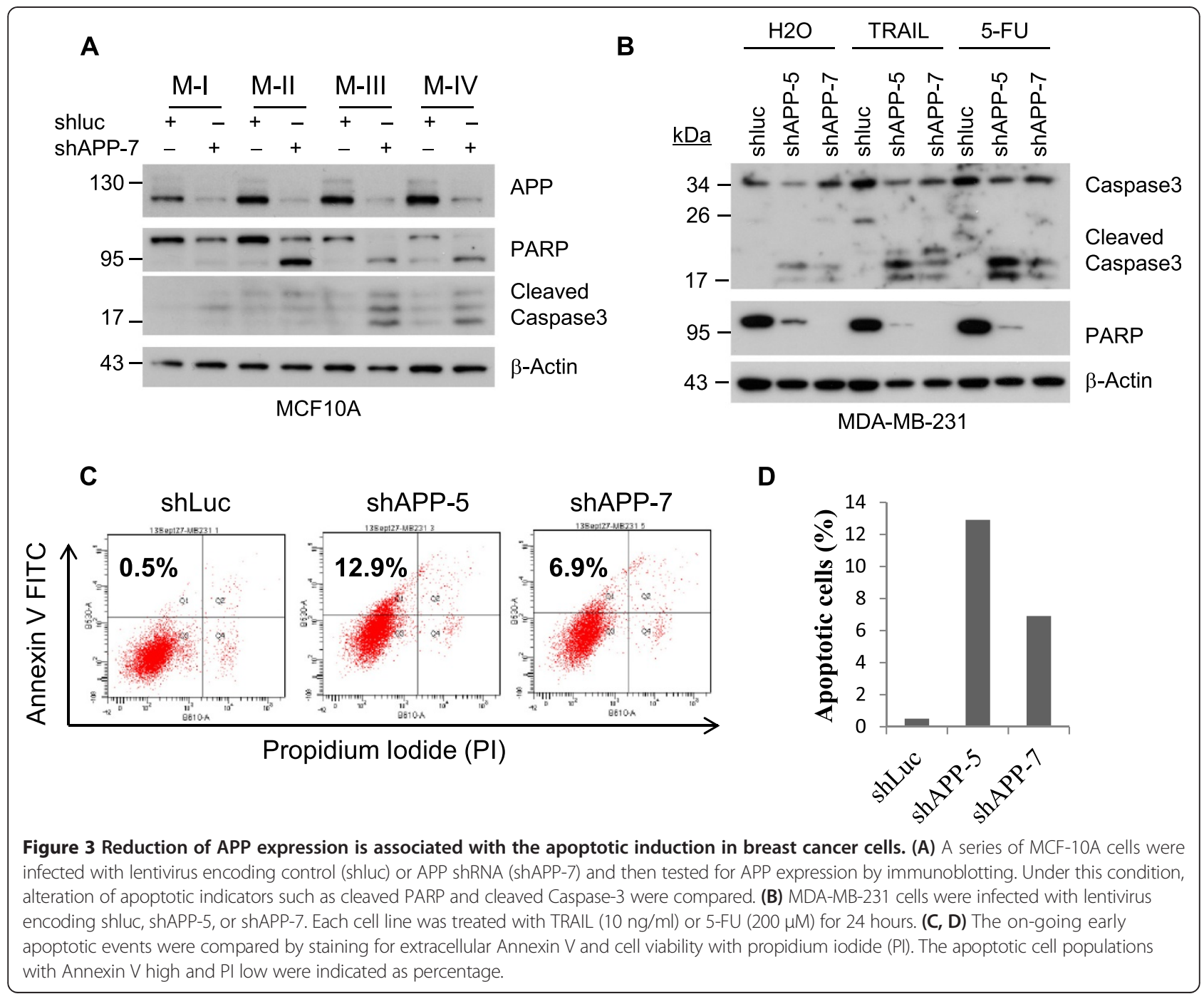


characteristics of 3D morphology may represent functional and genetic alteration of cancer cells as shown in altered E-cadherin expression [35,36], the 3D morphological change of APP-kd cells would result in behavioral and functional conversion. To confirm these in vitro findings further, we examined the effect of APP in the tumor xenograft mouse model. We injected the control or APP-kd MDA-MB-231 cells $\left(2 \times 10^{6}\right)$ subcutaneously to nude mice and maintained the mice for 6 weeks. Consistent with the findings in cell culture models, APP-kd cells showed significantly reduced tumor forming ability in vivo compared to control (Figure 4C). As an independent experiment, we subcutaneously injected further reduced numbers $\left(2.5 \times 10^{5}\right)$ of MDA-MB-231 cells (groups of control and APP-kd) and then measured tumor size over time. As a result of measurement up to 28-days post injection, there was a significant difference in tumor volume between control and APP-kd groups (Figure 4D). Tumor growth was negligible and difficult to measure in APP-kd group up to 22-days. These 3D culture and in vivo xenograft studies strongly support the role of APP in the promotion of breast cancer cell growth.

\section{APP is engaged in IGF1-induced AKT activation}

To understand the underlying mechanism of the effect of APP on breast cancer cells, we examined the signaling pathways potentially linked to $\mathrm{p} 27^{\mathrm{kip} 1}$ and apoptotic induction in APP-kd cells. MDA-MB-231 cells are known to possess both K-Ras and B-Raf oncogenic mutations [37] which regulate ERK pathway. Thus, we examined the effect of APP-kd on ERK activation. After EGF treatment, APP knockdown failed to reduce ERK activation at both basal and EGF-stimulated conditions of MDA-MB-231 cells (Figure 5A). In addition, NF-kB activation, which is important for cell survival, was unaffected by APP knockdown, as indicated by similar level of I-kB degradation and p-p65 (Ser536) post LPS stimulation (Figure 5B), suggesting both pathways are not likely responsible either for p2 $7^{\text {kip1 }}$ or apoptotic induction in APP-kd cells. Next, we examined IGF-1/AKT signaling pathway in APP-kd cells since AKT/FOXO signaling axis have been identified as critical signaling intermediates for breast cancer survival, growth, and migration as well as therapeutic drug resistance $[38,39]$. In the APP-kd cells, IGF-1-induced AKT phosphorylation at T308/S473 was evidently decreased
A

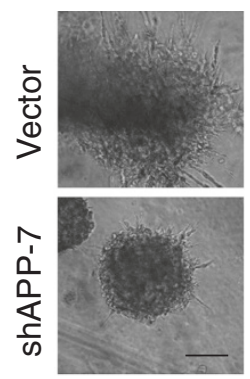

C

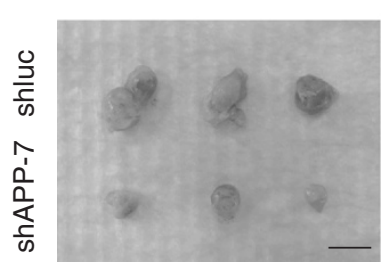

B

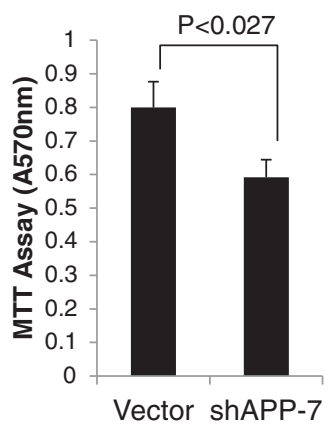

D

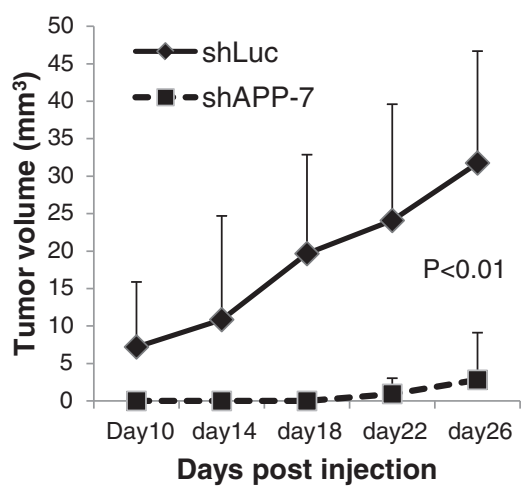

Figure 4 APP modulates breast cancer cell growth in 3D culture and in xenografted model. MDA-MB-231 cells were subjected to 3D Matrigel on-top assay. The cells were seeded $\left(2 \times 10^{4} /\right.$ well) in 48-well plate coated with Matrigel in triplicate and then cultured for 7 days with medium change in every two days. The morphology of growing cells were obtained (A) and followed by MTT assay (B). (C) The control and shAPP-7 MDA-MB-231 $\left(2 \times 10^{6}\right)$ cells were injected into nude mice s.c. $(n=6)$ and allowed to grow for 6 weeks. The grown tumors were excised and the grown tumor size compared. (Scale bar $=1 \mathrm{~cm})$ (D) The independent xenograft study $\left(2.5 \times 10^{5}\right.$ cells s.c injected; $n=5$, respectively) revealed that shAPP-7 MDA-MB-231 cell growth rate was largely decreased as compared to control group $(p<0.01)$. 
over total Akt and, concurrently, AKT-mediated GSK3 $\beta$ phosphorylation at Ser 9 was reduced (Figure 5C). Knock down of APP also significantly reduced the phosphorylation of FOXO, a main substrate of AKT and a transcription factor that regulates cell cycle progression through induction of cell cycle inhibitors including $\mathrm{p} 21^{\text {cip } 1}$ and $\mathrm{p} 27^{\mathrm{kip} 1}$. AKT is known to suppress FOXO family by inducing phosphorylation, nuclear export, and degradation which lead to subsequent $\mathrm{p} 21^{\mathrm{cip} 1}$ and/or $\mathrm{p} 27^{\text {kip1 }}$ reduction [40]. AKT can also directly phosphorylate and regulate p2 $7^{\text {kip1 }}$ cytoplasmic redistribution [41]. As demonstrated in Figure 2, p2 $7^{\text {kip } 1}$ remained in the nucleus for a longer time in APP-kd cells after serum release. Thus, it is likely that mitigated AKT activation in APP-kd cells resulted in higher p2 $7^{\text {kip } 1}$ expression and prolonged retention in nucleus. Next, we examined the change of GSK3 $\beta$ downstream target proteins (Figure 5D). The expression of $\beta$-catenin and its downstream targets such as survivin and CD44, but not Cyclin D1 were affected by knockdown of APP likely through AKT-GSK3 $\beta$ axis. These findings indicate that elevated APP expression in breast cancer may promote cell growth and survival by the induction of AKT-FOXO and AKT- GSK3 $\beta$ signaling cascades.

\section{APP reduction reduces cell motility in MDA-MB-231 cells}

Since APP expression has been linked to cell migration $[6,16]$, we explored the role of APP in cell migration and invasion of MDA-MB-231. The confluent control (shLuc) and APP-kd (shAPP-5 or shAPP-7) cell cultures were wounded and allowed to migrate into the wounded area in low serum containing medium with or without IGF-1. APP-kd cells showed very limited cell migration into the wounded space compared to the control cells in the absence of any stimulation. Moreover, upon IGF-1 treatment, more substantial difference in cell migration was observed between control and APP-kd cells (Figure 6A). Next, we assessed the cell migration ability of APP-kd MDA-MB-231 cells in transwell chambers. As was observed in the wound healing assay, APP-kd cells exhibited limited migration ability with about $50 \%$ reduction in

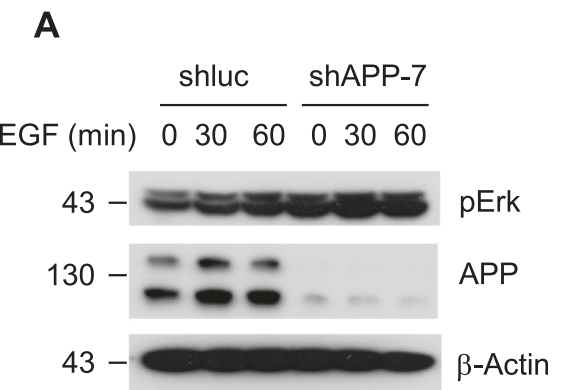

C

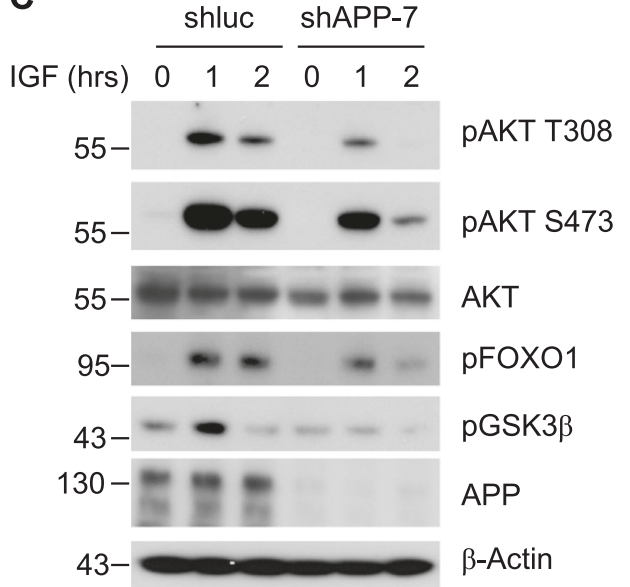

B

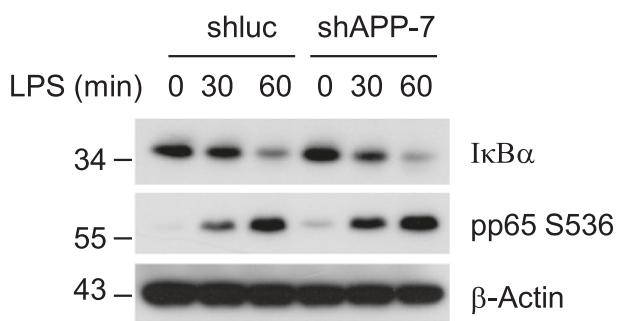

Figure 5 APP significantly impacts IGF-1-mediated activation of AKT and its downstream effectors. Both MDA-MB-231 control (shluc) and APP-kd (shAPP) cells were treated with EGF $(50 \mathrm{ng} / \mathrm{ml})$, LPS (100 ng/ml), or IGF-1 (100 ng/ml) as indicated. (A) EGF-mediated Erk activation was assessed in the APP knock-down cells post stimulation with EGF. (B) LPS-mediated activation of pro-inflammatory response in the APP knockdown cells was tested by demonstrating the level of IKBa expression and NF-KB activation (phosphorylated p65 at S536). (C) IGF-1-stimulated Akt activation and phosphorylation of Akt target proteins such as GSK3 $\beta$ (S9) and FOXO1 (T24) were examined. (D) APP affects the expression of $\beta$-Catenin, a target of GSK3ß, and its downstream targets such as Survivin and CD44, but not Cyclin D1. 
untreated cells and $75 \%$ reduction in IGF- 1 treated cells (Figure 6B and 6C). Notably, MDA-MB-231 control cells treated with IGF-1 showed spindle-like mesenchymal cell morphology whereas APP-kd cells did not, suggesting the potential role of APP during cell invasion and metastasis through regulation of epithelial-mesenchymal transition (EMT). Taken together, our data indicate that APP is involved in the regulation of cell motility triggered by IGF-1 and APP might be an attractive therapeutic target to prevent cell invasion and metastasis.

\section{Increased expression of APP in human breast cancer tissues} In order to examine the clinical relevance of APP expression in breast cancer, a tissue microarray (TMA) containing various grades of breast cancer tissues and normal breast tissues was analyzed with an anti-APP antibody (22C11). In the normal breast tissues, there was minimal to no staining of the breast epithelium. However, the vast majority of the invasive breast carcinomas showed some degree of APP expression. In total, there were 40 invasive breast carcinomas that could be evaluated on the TMA sections stained with $22 \mathrm{C} 11$ antibody. No staining was observed in 3 (7.5\%) of the cases. Weak staining was observed in $10(25 \%)$ of the cases, moderate staining in 18 (45\%), and strong staining in 9 (22.5\%). Though the number of cases in this series is small, there was a trend seen where the higher grade tumors showed more intense staining than the lower

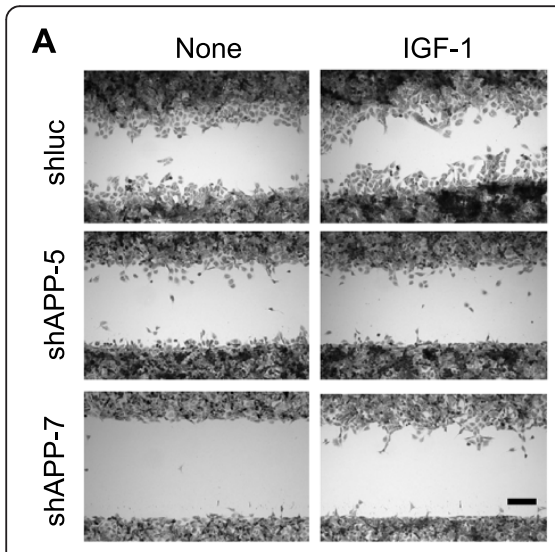

D
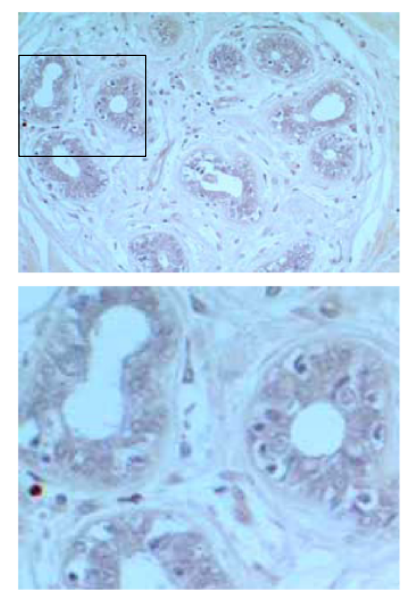
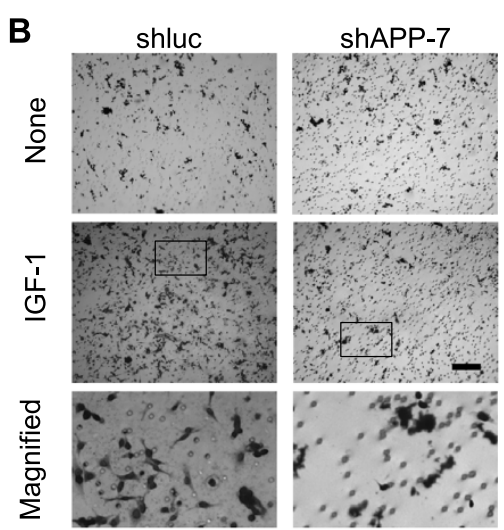

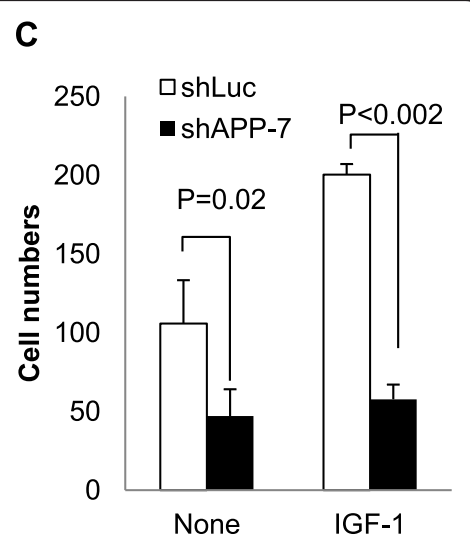

E

$\mathbf{F}$
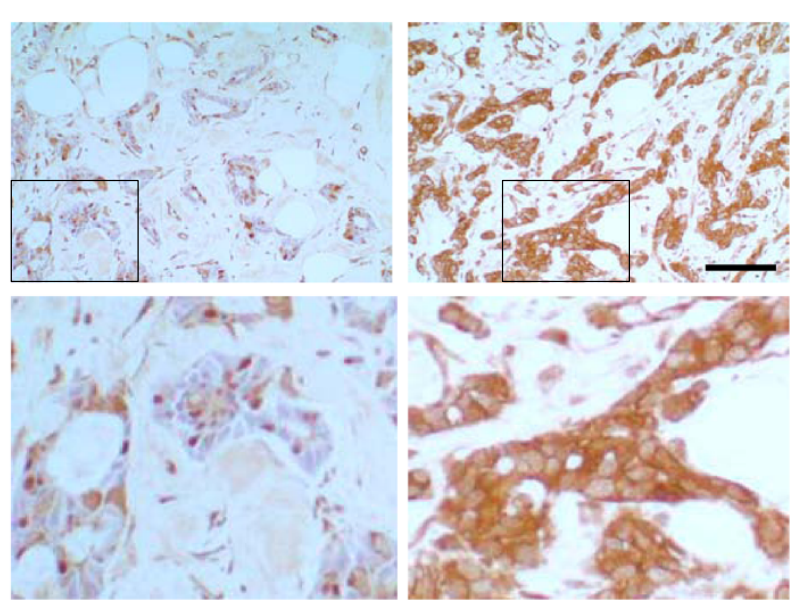

Figure 6 APP promotes cell migration of MDA-MB-231 and its expression is elevated in invasive breast cancer of human tissues. (A) The cell motility of APP knockdown (shAPP) MDA-MB-231 was examined in wound healing assay. Following the wounding, cells were untreated or treated with IGF-1 (25 ng/ml) for 18 hours in 0.1\% serum containing medium. Cells were then fixed and stained for clear demonstration (scale bar $=200 \mu \mathrm{m}$ ). (B) The role of APP for cell migration was evaluated in Boyden chamber assay in serum-free medium with or without IGF-1 (50 ng/ml) for 18 hours. The rectangular area was further magnified for demonstration of different cell morphology. (C) The migrated cells in panel B were counted in three randomly selected areas. (D) No staining for APP (22C11) is present in this normal terminal duct lobular unit. (E) The well-differentiated grade 1 invasive ductal carcinoma shows weak staining for APP. (F) The poorly-differentiated grade 3 invasive ductal carcinoma shows strong staining for APP. Scale bar $=100 \mu \mathrm{m}$. 
grade tumors overall (Figure 6D-F). These results strongly support our hypothesis that elevated APP expression has close correlation with tumor cell growth and progression.

\section{Discussion}

Our data strongly indicate the pathological role of APP in breast cancer. First, we demonstrated increased expression APP in breast cancer cells and its correlation with malignancy. Second, the inhibition of APP expression in breast cancer cells effectively prevents cell growth and motility in vitro and in vivo models. Third, we also demonstrated that APP is mechanistically linked to the AKT/FOXO and AKT/GSK3- $\beta$ pathways which are known to modulate cell growth, survival, and invasion of breast cancer cells through the regulation of target genes including p2 $7^{\text {kip1 }}$ and survivin. Importantly, knocking down of APP expression resulted in retarded cell growth in vitro and in vivo xenografted mouse model. We found that the slower cell proliferation was, in part, caused by the upregulated cell cycle inhibitor $\mathrm{p} 27^{\mathrm{kip} 1}$ expression in APP-kd cells. Thus, increased APP expression is inversely correlated with p2 $7^{\text {kip } 1}$ expression in malignant breast cancers. Since the reduced p2 $7^{\mathrm{kip} 1}$ expression is correlated with tumor aggressiveness and poor patient survival [29], this finding suggests that APP plays a significant role in regulation of p2 $7^{\text {kip } 1}$ in a malignant human breast cancer. In addition, knockdown of APP in breast cancers augmented apoptotic markers and it is likely that advanced breast cancers (M-II, M-III, and M-IV) with knockdown of APP are more prone to enter into apoptosis. Similarly, in addition to the result of MCF-10A cells, APP knockdown in MDAMB-231 promotes sensitivity to therapeutic treatments of TRAIL or 5-FU, implying that targeting APP in malignant breast cancers may promote the sensitivity to therapeutic drugs. Since homozygous APP-deficient mice are viable and normal in development [42], it seems that normal breast epithelial cell growth is not affected by knockdown of APP expression. However, advanced breast cancers may struggle to survive in the absence of APP, presumably because they have evolved to survive better, at least in part, in an APP-dependent manner. After the submission of this manuscript, Goodarzi et al. [43] published an article demonstrating the biological effect of APP in the regulation of breast cancer progression. Their results suggest that APP might suppress aggressiveness of breast cancer cells. While those results are not overlapped with the phenotype of our APP knockdown experiments, both reports strongly suggest the pathological role of APP in breast cancer pathogenesis. The discrepancy between two studies might be explained by different cellular conditions used in the studies. While they examined the role of APP under the condition of TARBP2 knockdown, our study examined a direct function of APP in the parental MDA-MB-231 cells without any other combinatorial genetic modifications. These results strongly suggest that the pathological role of APP in breast cancer pathogenesis works diversely upon the cellular context and this needs to be addressed in the future study.

Our data also suggest that APP is involved in IGF-1/ AKT signaling pathways, which are key regulatory pathways for cell growth and survival of breast cancer. APP-kd cells displayed mitigated AKT activation which leads to decreased inhibitory phosphorylation of GSK3 $\beta$ (Ser9) and FOXO1 (T24). GSK3 $\beta$ is known to suppress $\beta$-catenindependent oncogenic signaling pathway by phosphorylating $\beta$-Catenin [44,45]. Activation of $\beta$-catenin is reported in subgroup of triple negative breast cancers (i.e., aggressive breast cancers possessing lack of estrogen receptor, progesterone receptor, and Her2 receptor expression) and is associated with poor clinical outcomes [44]. On the other hand, FOXO family including FOXO1 can induce cell cycle inhibitors (e.g., p27 ${ }^{\text {kip1 }}$, p21 ${ }^{\text {cip1 }}$ ) and pro-apoptotic molecules (e.g., BIM, BNIP3, FASL, TRAIL, and survivin) [46]. The anti-apoptotic protein, survivin, is a family member of inhibitors of apoptosis (IAP) which embodies diverse cellular function, encompassing mitosis, metabolism, and survival by promoting adaptation to stresses [47]. As such, FOXO-survivin and $\beta$-catenin-survivin regulatory pathways are considered to play an essential role for the expression of survivin in breast cancer $[38,44]$. Thus, our results strongly suggest that APPmediated regulation of AKT/FOXO and AKT/GSK3 $\beta$ pathways are playing a significant role for breast cancer development. Supporting this hypothesis, a previous study demonstrated that SAPP $\alpha$ stimulates AKT/GSK3 $\beta$ pathway in neuronal cells and consequently resulted in its neuroprotective effect [48].

Interestingly, APP is also known to promote cell migration in neuronal progenitor cells [16] and engage in neuronal growth cone adhesion where it plays a role as an independently operating cell adhesion molecule for binding to extracellular matrices such as laminin [6]. Acquiring cell motility is a key aspect enabling cancer cells to invade into adjacent tissue and disseminate into the secondary organs. We therefore examined the cell motility and invasion ability of MDA-MB-231 after knocking down of APP expression. Upon stimulation with IGF-1 that promotes cell migration and cancer metastasis, APP-kd cells migrate slowly in response to IGF-1 partly due to limited activation of AKT. It is well known that AKT plays an important role in the process of EMT via repression of E-cadhrin [49]. In addition, $\beta$-catenin is also closely engaged in EMT and cell migration [50,51]. Our findings that APP is functionally linked with AKT activation and GSK-3 $\beta / \beta$-catenin pathways warrant the future study that elevated APP in malignant breast cancers is associated with dissemination of breast cancer into other target organs by promoting EMT process. 


\section{Conclusions}

In summary, we found that the expression of APP is increased both in mouse and human malignant breast cancer cell lines and similarly in human breast cancer tissues. The APP expression is important to regulate cell growth, apoptosis, and motility of breast cancer, possibly through engagement of AKT-mediated signaling pathways. Overall, our findings provide substantial groundwork for the pathophysiological function of APP and its underlying mechanism that promotes breast cancer malignancy.

\section{Abbreviations}

APP: Amyloid- $\beta$ precursor protein; TMA: Tissue microArray; IGF-1: Insulin-like growth factor-1; DAPI: Diamidino-2-phenylindole; TRAIL: Tumor necrosis factor (TNF)-related apoptosis-inducing ligand; 5-FU: 5-Fluorouracil.

\section{Competing interests}

The authors declare that they have no competing interests.

\section{Authors' contributions}

SL and HGL conceived and designed the study. SL, HK, HL, HGL, and YL contributed for the generation of stable cell lines and analyzed cellular and molecular effects of APP knockdown in cell growth, apoptosis, and invasion (cell proliferation assay, cell cycle analysis, RT-PCR, flow cytometry, Western blots); HLG and HGL analyzed human breast cancer tissue array data. SL, SK, $J$, and HGL participated in the data analysis; BY and SL coordinated the mouse xenograft study and SL and HGL wrote the manuscript. All authors have read and approved the final manuscript.

\section{Acknowledgements}

We thank Sandra Siedlak for the technical assistance. This study was supported by the National Institutes of Health (AG028679) to HGL.

\section{Author details \\ ${ }^{1}$ Department of Pediatrics, Case Comprehensive Cancer Center, Case Western Reserve University School of Medicine, 2103 Cornell Road, Cleveland, $\mathrm{OH}$ 44106, USA. Department Pathology, Case Western Reserve University School of Medicine, 2103 Cornell Road, Cleveland, OH 44106, USA. ${ }^{3}$ Department Pharmacology, Case Western Reserve University School of Medicine, Cleveland, OH 44106, USA. ${ }^{4}$ Department of Human and Molecular Genetics, Virginia Commonwealth University School of Medicine, Richmond, VA, USA. ${ }^{5} \mathrm{CHA}$ Cancer Institute, CHA University, Seoul 135-081, Korea. ${ }^{6}$ The Angie Fowler Adolescent and Young Adult Cancer Institute, University Hospitals Rainbow Children's Hospital, Cleveland, OH 44106, USA.}

Received: 15 April 2014 Accepted: 5 December 2014 Published: 10 December 2014

\section{References}

1. O'Brien RJ, Wong PC: Amyloid precursor protein processing and Alzheimer's disease. Annu Rev Neurosci 2011, 34:185-204.

2. Hardy JA, Higgins GA: Alzheimer's disease: the amyloid cascade hypothesis. Science 1992, 256(5054):184-185.

3. De Strooper B, Annaert W: Proteolytic processing and cell biological functions of the amyloid precursor protein. J Cell Sci 2000, 113(Pt 11):1857-1870.

4. Jacobsen KT, Iverfeldt K: Amyloid precursor protein and its homologues: a family of proteolysis-dependent receptors. Cell Mol Life Sci 2009, 66(14):2299-2318.

5. Sheng B, Song B, Zheng Z, Zhou F, Lu G, Zhao N, Zhang X, Gong Y: Abnormal cleavage of APP impairs its functions in cell adhesion and migration. Neurosci Lett 2009, 450(3):327-331.

6. Sosa LJ, Bergman J, Estrada-Bernal A, Glorioso TJ, Kittelson JM, Pfenninger $\mathrm{KH}$ : Amyloid precursor protein is an autonomous growth cone adhesion molecule engaged in contact guidance. PLoS One 2013, 8(5):e64521.

7. Baratchi S, Evans J, Tate WP, Abraham WC, Connor B: Secreted amyloid precursor proteins promote proliferation and glial differentiation of adult hippocampal neural progenitor cells. Hippocampus 2012, 22(7):1517-1527.

8. Hoffmann J, Twiesselmann C, Kummer MP, Romagnoli P, Herzog V: A possible role for the Alzheimer amyloid precursor protein in the regulation of epidermal basal cell proliferation. Eur J Cell Biol 2000, 79(12):905-914.

9. Pietrzik CU, Hoffmann J, Stober K, Chen CY, Bauer C, Otero DA, Roch JM Herzog V: From differentiation to proliferation: the secretory amyloid precursor protein as a local mediator of growth in thyroid epithelial cells. Proc Natl Acad Sci U S A 1998, 95(4):1770-1775.

10. Meng JY, Kataoka $\mathrm{H}$, Itoh $\mathrm{H}$, Koono M: Amyloid beta protein precursor is involved in the growth of human colon carcinoma cell in vitro and in vivo. Int J Cancer 2001, 92(1):31-39.

11. Hansel DE, Rahman A, Wehner S, Herzog V, Yeo CJ, Maitra A: Increased expression and processing of the Alzheimer amyloid precursor protein in pancreatic cancer may influence cellular proliferation. Cancer Res 2003, 63(21):7032-7037.

12. Krause K, Karger S, Sheu SY, Aigner T, Kursawe R, Gimm O, Schmid KW, Dralle $H$, Fuhrer D: Evidence for a role of the amyloid precursor protein in thyroid carcinogenesis. J Endocrino/ 2008, 198(2):291-299.

13. Takayama K, Tsutsumi S, Suzuki T, Horie-Inoue K, Ikeda K, Kaneshiro K, Fujimura T, Kumagai J, Urano T, Sakaki Y, Shirahige K, Sasano H, Takahashi S, Kitamura T, Ouchi Y, Aburatani H, Inoue S: Amyloid precursor protein is a primary androgen target gene that promotes prostate cancer growth. Cancer Res 2009, 69(1):137-142.

14. Venkataramani V, Rossner C, Iffland L, Schweyer S, Tamboli IY, Walter J, Wirths O, Bayer TA: Histone deacetylase inhibitor valproic acid inhibits cancer cell proliferation via down-regulation of the alzheimer amyloid precursor protein. J Biol Chem 2010, 285(14):10678-10689.

15. Takagi K, Ito S, Miyazaki T, Miki Y, Shibahara Y, Ishida T, Watanabe M, Inoue S, Sasano H, Suzuki T: Amyloid precursor protein (APP) in human breast cancer: an androgen-induced gene associated with cell proliferation. Cancer Sci 2013, 104(11):1532-1538.

16. Young-Pearse TL, Bai J, Chang R, Zheng JB, LoTurco JJ, Selkoe DJ: A critical function for beta-amyloid precursor protein in neuronal migration revealed by in utero RNA interference. J Neurosci 2007, 27(52):14459-14469.

17. Young-Pearse TL, Chen AC, Chang R, Marquez C, Selkoe DJ: Secreted APP regulates the function of full-length APP in neurite outgrowth through interaction with integrin beta1. Neural Dev 2008, 3:15.

18. Jemal A, Bray F, Center MM, Ferlay J, Ward E, Forman D: Global cancer statistics. Cancer J Clin 2011, 61(2):69-90.

19. Hong S, Lim S, Li AG, Lee C, Lee YS, Lee EK, Park SH, Wang XJ, Kim SJ: Smad7 binds to the adaptors TAB2 and TAB3 to block recruitment of the kinase TAK1 to the adaptor TRAF2. Nat Immunol 2007, 8(5):504-513.

20. Harris JA, Devidze N, Verret L, Ho K, Halabisky B, Thwin MT, Kim D, Hamto P, Lo I, Yu GQ, Palop JJ, Masliah E, Mucke L: Transsynaptic progression of amyloid-beta-induced neuronal dysfunction within the entorhinalhippocampal network. Neuron 2010, 68(3):428-441.

21. Minn AJ, Gupta GP, Siegel PM, Bos PD, Shu W, Giri DD, Viale A, Olshen AB, Gerald WL, Massague J: Genes that mediate breast cancer metastasis to lung. Nature 2005, 436(7050):518-524.

22. Tang B, Vu M, Booker T, Santner SJ, Miller FR, Anver MR, Wakefield LM: TGF-beta switches from tumor suppressor to prometastatic factor in a model of breast cancer progression. J Clin Invest 2003, 112(7):1116-1124.

23. Miller FR, Soule HD, Tait L, Pauley RJ, Wolman SR, Dawson PJ, Heppner GH: Xenograft model of progressive human proliferative breast disease. J Natl Cancer Inst 1993, 85(21):1725-1732.

24. Aslakson CJ, Miller FR: Selective events in the metastatic process defined by analysis of the sequential dissemination of subpopulations of a mouse mammary tumor. Cancer Res 1992, 52(6):1399-1405.

25. Mattson MP: Cellular actions of beta-amyloid precursor protein and its soluble and fibrillogenic derivatives. Physiol Rev 1997, 77(4):1081-1132.

26. Kummer C, Wehner S, Quast T, Werner S, Herzog V: Expression and potential function of beta-amyloid precursor proteins during cutaneous wound repair. Exp Cell Res 2002, 280(2):222-232.

27. Sherr CJ, Roberts JM: CDK inhibitors: positive and negative regulators of G1-phase progression. Genes Dev 1999, 13(12):1501-1512.

28. Caldon CE, Daly RJ, Sutherland RL, Musgrove EA: Cell cycle control in breast cancer cells. J Cell Biochem 2006, 97(2):261-274.

29. Chu IM, Hengst L, Slingerland JM: The Cdk inhibitor p27 in human cancer: prognostic potential and relevance to anticancer therapy. Nat Rev 2008, 8(4):253-267. 
30. Wander SA, Zhao D, Slingerland JM: p27: a barometer of signaling deregulation and potential predictor of response to targeted therapies. Clin Cancer Res 2011, 17(1):12-18.

31. Mahalingam D, Szegezdi E, Keane M, de Jong S, Samali A: TRAIL receptor signalling and modulation: Are we on the right TRAIL? Cancer Treat Rev 2009, 35(3):280-288.

32. Joensuu $\mathrm{H}$, Gligorov J: Adjuvant treatments for triple-negative breast cancers. Ann Oncol 2012, 23(Suppl 6):vi40-vi45.

33. Lee GY, Kenny PA, Lee EH, Bissell MJ: Three-dimensional culture models of normal and malignant breast epithelial cells. Nat Methods 2007, 4(4):359-365.

34. Schmeichel KL, Bissell MJ: Modeling tissue-specific signaling and organ function in three dimensions. J Cell Sci 2003, 116(Pt 12):2377-2388.

35. Weigelt B, Bissell MJ: Unraveling the microenvironmental influences on the normal mammary gland and breast cancer. Semin Cancer Biol 2008, 18(5):311-321.

36. Kenny PA, Lee GY, Myers CA, Neve RM, Semeiks JR, Spellman PT, Lorenz K, Lee EH, Barcellos-Hoff MH, Petersen OW, Gray JW, Bissell MJ: The morphologies of breast cancer cell lines in three-dimensional assays correlate with their profiles of gene expression. Mol Oncol 2007, 1(1):84-96.

37. Hollestelle A, Elstrodt F, Nagel JH, Kallemeijn WW, Schutte M: Phosphatidylinositol-3-OH kinase or RAS pathway mutations in human breast cancer cell lines. Mol Cancer Res 2007, 5(2):195-201.

38. Chakrabarty A, Bhola NE, Sutton C, Ghosh R, Kuba MG, Dave B, Chang JC, Arteaga CL: Trastuzumab-resistant cells rely on a HER2-PI3K-FoxO-survivin axis and are sensitive to PI3K inhibitors. Cancer Res 2013, 73(3):1190-1200.

39. Rexer BN, Arteaga CL: Optimal targeting of HER2-PI3K signaling in breast cancer: mechanistic insights and clinical implications. Cancer Res 2013, 73(13):3817-3820.

40. Tzivion G, Dobson M, Ramakrishnan G: FoxO transcription factors; Regulation by AKT and 14-3-3 proteins. Biochim Biophys Acta 2011, 1813(11):1938-1945.

41. Clarke RB: p27KIP1 phosphorylation by PKB/Akt leads to poor breast cancer prognosis. Breast Cancer Res 2003, 5(3):162-163.

42. Zheng H, Jiang M, Trumbauer ME, Hopkins R, Sirinathsinghij DJ, Stevens KA, Conner MW, Slunt HH, Sisodia SS, Chen HY, Van der Ploeg LH: Mice deficient for the amyloid precursor protein gene. Ann N Y Acad Sci 1996, 777:421-426.

43. Goodarzi H, Zhang S, Buss CG, Fish L, Tavazoie S, Tavazoie SF: Metastasissuppressor transcript destabilization through TARBP2 binding of mRNA hairpins. Nature 2014, 513(7517):256-260.

44. King TD, Suto MJ, Li Y: The Wnt/beta-catenin signaling pathway: a potential therapeutic target in the treatment of triple negative breast cancer. J Cell Biochem 2012, 113(1):13-18.

45. Incassati A, Chandramouli A, Eelkema R, Cowin P: Key signaling nodes in mammary gland development and cancer: beta-catenin. Breast Cancer Res 2010, 12(6):213.

46. Yang JY, Hung MC: Deciphering the role of forkhead transcription factors in cancer therapy. Curr Drug Targets 2011, 12(9):1284-1290.

47. Srinivasula SM, Ashwell JD: IAPs: what's in a name? Mol Cell 2008 30(2):123-135

48. Jimenez S, Torres M, Vizuete M, Sanchez-Varo R, Sanchez-Mejias E, TrujilloEstrada L, Carmona-Cuenca I, Caballero C, Ruano D, Gutierrez A, Vitorica J: Age-dependent accumulation of soluble amyloid beta (Abeta) oligomers reverses the neuroprotective effect of soluble amyloid precursor proteinalpha (sAPP(alpha)) by modulating phosphatidylinositol 3-kinase (PI3K)/ Akt-GSK-3beta pathway in Alzheimer mouse model. J Biol Chem 2011, 286(21):18414-18425.

49. Larue L, Bellacosa A: Epithelial-mesenchymal transition in development and cancer: role of phosphatidylinositol 3' kinase/AKT pathways. Oncogene 2005, 24(50):7443-7454.

50. Gilles C, Polette M, Mestdagt M, Nawrocki-Raby B, Ruggeri P, Birembaut P, Foidart JM: Transactivation of vimentin by beta-catenin in human breast cancer cells. Cancer Res 2003, 63(10):2658-2664.

51. Roxanis I: Occurrence and significance of epithelial-mesenchymal transition in breast cancer. J Clin Pathol 2013, 66(6):517-521.

doi:10.1186/1471-2407-14-928

Cite this article as: Lim et al:: Amyloid- $\beta$ precursor protein promotes cell proliferation and motility of advanced breast cancer. BMC Cancer 2014 14:928.

\section{Submit your next manuscript to BioMed Central and take full advantage of:}

- Convenient online submission

- Thorough peer review

- No space constraints or color figure charges

- Immediate publication on acceptance

- Inclusion in PubMed, CAS, Scopus and Google Scholar

- Research which is freely available for redistribution 